\title{
Gestão pela qualidade em Instituições Hospitalares
}

Ednólia Gomes Varjão Fernandes ${ }^{1}$; Gizelda Vasconcelos Vieira de Alcântara ${ }^{2}$; Geraldo Sadoyama ${ }^{3}$

\section{Resumo}

O tema qualidade é muito discutido e encontra-se em qualquer ambiente, seja ele de trabalho ou não. Hoje existe amplas abordagens e diferentes discussões sobre sistema de qualidade, gestão da qualidade, qualidade de vida, qualidade de vida no trabalho, atendimento ao cliente com qualidade e qualidade na assistência de saúde prestada. As empresas de bens ou serviços e as organizações ao longo dos anos e com o crescente processo de globalização começaram a enfrentar um mercado econômico muito competitivo e inovador. Ao mesmo tempo há uma disputa dentro deste mercado, diversificado e com inúmeros concorrentes, todos esses fatores contribuíram para que as organizações e empresas buscassem e ampliassem as discussões e o conhecimento no que se refere aos processos que envolve a área de gestão, qualidade, área de gestão de qualidade dos produtos desenvolvidos e mesmo dos serviços prestados. A percepção que o cliente tem da organização passou a ser uma informação relevante para as mesmas. Satisfazer o cliente externo, é um ponto primordial para manter-se na disputa dentro do mercado econômico. $\mathrm{E}$ todo esse contexto se direcionou também para a área de saúde onde atualmente os clientes que procuram os estes serviços estão cada vez mais exigentes no que se refere a qualidade e segurança da assistência prestada. A segurança do paciente é uma discussão em destaque, pois é uma importante dimensão da qualidade. Os eventos adversos que ocorrem nas Instituições de saúde, em sua maioria possuem protocolos, barreiras para minimizar ou mesmo evitar que o evento adverso ocorra.

1

Enfermeira, formada pela UFPR, pós-graduada em Enfermagem do Trabalho -São Camilo, em Unidade de Terapia Intensiva- Facisa e Docência do Ensino Superior - Fac. Senac , aluna Especial do Mestrado Profissional em Gestão Organizacional pela UFG campus Catalão

2

2 Médica, formada pela UFU Especializada em Ginecologia- Obstetrícia e Gravidez de alto Risco UFU

3 Biólogo, formado pela UFU, Doutor em Imunologia e Parasitologia, Professor do Mestrado Profissional em Gestão Organizacional pela UFG - campus Catalão. 
Palavras Chave: qualidade de serviços, segurança do paciente, serviços de saúde

\section{Introdução}

As Instituições de saúde evoluíram muito com o passar dos anos. $\mathrm{Na}$ idade média, o atendimento ao indivíduo doente tinha o propósito de curar a alma e não a patologia. A princípio os hospitais eram vistos como locais para colocar as pessoas doentes e afasta-las do convívio social, pois não se conhecia muito sobre as doenças. Influenciado pelo crescimento no ramo da ciência, economia e mudanças no setor político, o lado humano das pessoas começou a ser um pouco mais percebido. Com o advento da Revolução Industrial, veio o desenvolvimento de várias áreas, dentre elas a Medicina e com este cenário, os hospitais começam a ser vistos com local de tratamento. A partir do século XX até os momentos atuais, o que se observa é uma evolução contínua na área de saúde (LUONGO; et al 2011).

Alves (2013), complementa que o erro tem uma estreita relação com a desvalorização da qualidade do profissional. Os profissionais que não erram são os melhores e aqueles que cometem erros devem ser afastados da assistência. Os impactos frente a mídia dessas situações de falhas na assistência ganham destaque na sociedade. As falhas, os erros ocorrem com frequência.

De acordo com Bueno e Fossarella (2012), com os avanços tecnológicos e crescimento nas diferentes áreas de conhecimento, a complexidade em relação a assistência prestada também foi se tornando cada vez mais visível. Frente a todo esse desenvolvimento, o risco de ocorrer erros se tornou mais comum. Como resultado desta situação era adotada uma conduta de caráter punitivo. Essa discussão seguiu por longo período da história. Em 1918 começam a surgir trabalhos onde a principal discussão foi apresentar o predomínio e que existem formas de evitar as doenças causadas por erros médicos.

Reis, Martins e Laguardia (2013), complementam que houve uma preocupação com as inúmeras ocorrências dos eventos adversos (EA) relacionados a assistência prestada, onde surgiram pesquisas e estudos com o propósito de discutir a segurança do paciente. A partir do ano 2000 a preocupação com a segurança do paciente é pauta de discussão em todo mundo e passa a ser reconhecida como importante dimensão da qualidade. No ano de 2004, a Organização Mundial de Saúde estabeleceu a Aliança Mundial para a Segurança do Paciente, com o objetivo de determinar e reconhecer fatores importantes no que se refere a segurança do paciente.

\section{Desenvolvimento}

\subsection{Conceito de qualidade nos serviços de saúde}

Bonato (2011), traz argumentos que o conceito de qualidade ampliou sua dimensão nas organizações nos anos 90 . Discutir o conceito de qualidade direcionou as empresas a discutirem sobre as suas perspectivas de futuro, sobre o processo de sustentabilidade e sobre a competitividade de mercado. 
As organizações refletiram e optaram por ações voltadas para o planejamento, performance, desenvolvimento e melhoria. Observou-se um crescimento do indivíduo quanto profissional levando a ampliando sua capacidade e criatividade.

Acrescentado a discussão sobre o conceito de qualidade, Jericó e Balsanelli (2005) apontam que o conceito de qualidade se encontra muito abrangente e está envolvido diretamente com outras áreas da ciência, e colocam que este pode ser visto, trabalhado e desenvolvido como uma nova metodologia. Ainda segundo os autores, a qualidade tem acompanhado o processo de globalização, principalmente no que se refere as organizações e a proposta atual direciona para o desenvolvimento de produto ou serviço que proporcione ampla satisfação ao cliente.

Bonato (2011), afirma que o termo qualidade interfere e age em diferentes segmentos e grupos sociais. Dentro dos segmentos de trabalho pode ser mencionado as instituições de saúde, seja ela pública ou privada. A exemplo destas instituições encontram-se os hospitais, estes passaram por grande evolução no decorrer da história, principalmente no final do século XIX e início do século XX, influenciado pelo surgimento e crescimento da medicina e avanços no setor de tecnologia. O mesmo saiu do cenário onde as pessoas que não possuíam boas condições financeiras eram levadas para morrer até o cenário atual, onde é encontrado tecnologia, boa infraestrutura, atendimento e assistência a diferentes pessoas da sociedade, crescimento em várias áreas de atuação como por exemplo clínicas, laboratórios dentre outras especialidades.

Junior e Matsuda (2011) contribuem com a discussão referindo que a qualidade ganhou dimensões em todo o mundo devido à grande exigência dos clientes externos. Afirmam que não é diferente na área de saúde, onde as discussões se fortaleceram nos Estados Unidos na década de vinte, com o aparecimento dos argumentos sobre qualidade dos procedimentos médicos durante a assistência prestada e mesmo o desenvolvimento das atividades realizadas pelos profissionais. Em nosso país, há referência que o primeiro trabalho criado referente a qualidade dos serviços hospitalares tenha sido criado na década de trinta, onde um profissional da área médica desenvolveu uma ficha onde era especificada como o serviço desenvolvido pela Instituição poderia ser realizado.

Para Fadel e Filho (2009), qualidade está diretamente relacionada as formas de gerenciamento, associada ao conhecimento do sistema gestão proposto, com o objetivo de proporcionar mudanças crescentes em todo o processo, valorizando o conhecimento das pessoas envolvidas. Os clientes têm percepções diferentes no que se refere a qualidade do serviço prestado, ficando em muitos aspectos a palavra qualidade nos serviços de saúde voltada para um sentido subjetivo. 


\subsection{Avaliação da qualidade nos serviços de saúde}

Bueno e Fassarella, (2012), colocam que dentro do contexto histórico que envolve a segurança do paciente, um dos fatos importantes ocorridos foi a ciração da Agência Nacional de Segurança do Paciente no Reino Unido. Em nosso país, as pesquisas ganharam destaque por volta do ano 2000, influenciado pelas discussões referente as certificações das Instituições de saúde, através de avaliações realizadas sob forma de acreditação. As avaliações mostravam que os serviços não se encontravam organizados para promover e garantir uma assistência segura. Próximo á esses fatores se encontra o profissional com suas limitações. Em 1999 é criada á ONA Organização Nacional de Acreditação e no ano de 2002 é oficializado pela Agência Nacional de Vigilância Sanitária o Sistema Brasileiro de Acreditação. Ainda de acordo com as autoras, a acreditação permite verificar e coordenar os prováveis erros na organização, sendo os mesmos voltados para a assistência direta ou indireta com o cliente.

De acordo com Bonato (2011), o processo de acreditação direciona para uma participação voluntária das organizações de saúde e acrescentam que o processo apresenta o propósito garantir a melhoria do desempenho, avaliação da qualidade e segurança da assistência prestada pelos serviços de saúde seja de caráter público ou privado. O sistema de avaliação realiza a análise de todos os serviços da Instituição e segue os padrões internacionais e tem reflexos sobre colaboradores da equipe multiprofissional bem como 0 paciente. A organização que define 0 indicador de saúde que será importante para o desenvolvimento do seu trabalho.

Moura et al (2009), contribuem com a discussão trazendo uma abordagem referente aos indicadores, o mesmo tem uma representação quantitativa do que se pretende avaliar. Os indicadores fornecem informações importantes sobre o processo que está sendo trabalhado, são considerados ferramentas que direcionam ações para área de gestão hospitalar, programas de educação, atualização na área de saúde, acompanhar o desenvolvimento dos processos e avaliar das ações desenvolvidas.

A avaliação da qualidade hospitalar pode ser trabalhada com outros instrumentos, como por exemplo o modelo SERVPEF. Este modelo se direcionou apenas para a percepção da execução dos serviços, esta escala considera as dimensões da qualidade presentes na escala SERVQUAL. A escala SERVFEF aborda cinco dimensões: tangibilidade, confiabilidade, atendimento ou prontidão na resposta, garantia ou segurança e empatia. (FREITAS; COZENDEY, 2008). 


\subsection{Gestão pela qualidade}

De acordo com Fadel e Filho (2009), gerenciar serviços de saúde que se envolvem ações relacionadas a prestação do serviço e não a um produto tangível, torna este tipo de gestão um processo delicado. Neste contexto a relação dos profissionais com o cliente deve ser maleável, pois o envolvimento do cliente dentro desse processo é muito presente. As organizações necessitam permanecer em constante avaliação e transformação, pois as pessoas que procuram estes serviços procuram por qualidade no atendimento e nessa situação, a percepção da qualidade da assistência recebida está à frente da assistência esperada.

Atualmente existem diferentes formas de trabalho para serem adquiridas no que refere a desenvolver o processo de gestão, em nosso país o Sistema de Gestão pela Qualidade Total ou como também é conhecido, Gestão pela Qualidade tem trazido resultado positivo para estas organizações. A meta desse processo é alcançar a satisfação dos clientes e também resultados eficientes para os serviços de saúde. Este modelo é direcionado para a proposta de se trabalhar com os colaboradores no que se refere trabalhos em grupos, promover o desenvolvimento da criatividade e envolver o cliente. Este processo é baseado em ações previamente planejadas (JUNIOR; MATSUDA, 2011).

Jericó e Balsanelli (2005) complementam que o modelo de Gestão pela Qualidade Total já se encontra presente como disciplina na área de formação dos profissionais enfermeiros. É um modelo que se iniciou na indústria japonesa e que em com o passar do tempo se expandiu para outras áreas.

Souza et al (2009) contribuem acrescentando a importância da avaliação de desempenho para o acompanhamento, monitoramento, verificação e avaliação do processo de gestão hospitalar. A avaliação dos indicadores fornece meios para vincular ações que envolvem a gestão de pessoas, insumos utilizados na assistência, equipamentos tecnológicos, enfim, tem o propósito de realizar uma gestão de forma correta e com qualidade. A acreditação hospitalar se encontra associada a este processo.

\section{Considerações finais}

As organizações de saúde com o passar dos anos e com o crescimento da área de ciência e da tecnologia vem buscando qualidade e segurança nos serviços prestados. Com todo esse crescimento e desenvolvimento os problemas relacionados aos erros cometidos pelos profissionais da área de saúde começaram a ser mais evidenciados. O trabalhador que cometia o erro era visto como um profissional desqualificado e irresponsável, a falha era tratada com ações punitivas.

Após várias discussões e estudos relacionado ao evento adverso, atualmente existem programas e protocolos que visam prevenir e minimizar a ocorrência dos mesmos. 
O cliente que procura os serviços de saúde está cada vez mais exigente, e para as organizações atender este cliente é um desafio diário, pois enfrenta um mercado dinâmico e cada vez mais competitivo.

As organizações buscam por modelos de Gestão e instrumentos que direcionem ao planejamento, o controle, a avaliação dos processos institucionais. Avaliar a qualidade é complexo na área de saúde, pois neste sentido apresenta um conceito subjetivo. A acreditação é um sistema de avalição voluntário que tem como objetivo direcionar a qualidade e segurança da assistência, por meio de padrões já referenciados. 


\title{
Quality management in Hospital Institutions
}

\begin{abstract}
The quality issue is much discussed and is in any environment, be it work or not. Today there is broad different approaches and discussions on quality system, quality management, and quality of life, quality of working life, customer service quality and quality of provided health care. Companies of goods or services and organizations over the years and the increasing globalization process began to face a very competitive and innovative market economy. At the same time there is a dispute within this market, diverse and numerous competitors, all these factors contributed to the organizations and companies seek and broaden the discussions and knowledge with regard to processes involving the area of management, quality, area the management quality of the developed products and even services. The perception that the client has the organization has become a relevant information to them. Satisfy the external customer, it is a key point to keep in contention within the economic market. And all this context is directed to the health area where currently the customers seeking these services are increasingly demanding as regards the quality and safety of care. Patient safety is a featured discussion; it is an important dimension of quality. Adverse events occurring in health institutions, most have protocols, barriers to minimize or even prevent the adverse event occurs.
\end{abstract}

Keywords: service quality, patient safety, health care 


\section{Referências}

ALVES, E.A.V. Segurança do Paciente: do erro á prevenção do risco. n 2., 2013. Brasília. In: Anais do III Congresso Iberoamericano de Direito Sanitário/ II Congresso Brasileiro de Direito Sanitário. Caderno Iberoamericano Direito Sanitário: 2013. p. 10.

BALSANELLI, A. P; JERICÓ, M.C. Os reflexos da Gestão pela qualidade total em instituições hospitalares brasileiras. Acta Paul Enfermagem. fev./ mar. 2005.

BONATO, Vera Lúcia. Gestão de qualidade em saúde: melhorando assistência ao cliente. O Mundo da Saúde. p. 319- 331. 2011.

BUENO, A. A. B; FASSARELA, C.S. Segurança do Paciente: uma reflexão sobre sua trajetória histórica. Patient: a reflection on its historical trajectory. Revista Rede de cuidados em Saúde. V 6, n. 1. p.1-9. 2012.

FADEL, M. A. V; FILHO, G.I.R. Percepção da qualidade em serviços públicos de saúde: um estudo de caso. Revista de Administração Pública. p. 07-22. jan./jul 2009.

FREITAS, A.L.P; COZENDY, I.M. Um modelo SERVPEF para avaliação dos serviços hospitalares. Rio de Janeiro. In: XXVIII Encontro Nacional de engenharia de produção. 2008. p. 13.

JUNIOR, J.A.B; MATSUDA, L.M. O Enfermeiro no Gerenciamento à qualidade em serviço hospitalar de emergência: revisão integrativa de literatura. Revista Gaúcha de Enfermagem. dez./ 2011.

LUONGO, J. Gestão de qualidade em saúde. São Paulo: Rideel, 2011. 317p MOURA, G. S. S. et al. Construção e implantação de dois indicadores de qualidade assistencial de enfermagem. Revista Gaúcha de Enfermagem. p. 136- 140. mar./ 2009.

REIS, T. C; MARTINS, M; LAGUARDIA, J. A segurança do paciente como dimensão da qualidade do cuidado de saúde - um olhar sobre a literatura. Ciência \& Saúde Coletiva. v. 18, n. 7, p. 2029 -2036. jul./ 2013.

SOUZA, A. A. et al. Controle de Gestão em Organizações Hospitalares. Revista de gestão USP. v.16, n. 3, p. 15-29. jul./set. 2009. 